\section{Osteopoikilosis: Avoiding Misdiagnosis of this Unusual Incidental Finding. A Case Report}

\author{
Tarek Boutefnouchet*, Thomas Laios and Socrates \\ Kalogrianitis
}

Department of Trauma and Orthopaedics, Queen Elizabeth Hospital, University Hospital Birmingham, Mindelsohn Way, Edgbaston, Birmingham, United Kingdom

\begin{abstract}
A twenty-year-old male patient was referred to a specialist upper limb orthopaedic clinic with moderate elbow pain, which started after he took up martial arts training. The initial plain radiographs had caused grave concerns to the non-orthopaedic physicians. By the time the patient was reviewed in clinic his symptoms had resolved completely. A diagnosis of osteopoikilosis was made and confirmed on MRI scan. Osteopoikilosis remains a rare and incidental finding, once adequately identified invasive diagnostic or therapeutic procedures should be avoided. We report a typical case with a review of the literature pertinent to differential diagnoses.
\end{abstract}

Keywords: Osteodysplasia; Osteopoikilosis; Spotted bone

\section{Case Presentation}

A twenty-year-old male patient presented to his general practitioner with an insidious onset elbow joint pain. There was no history of trauma to the elbow, however in the three months preceding the onset of symptoms the patient started vigorous martial arts training. There was no other medical background in the clinical history. At the initial stage this was treated as minor soft tissue trauma related to sports. A course of simple analgesia and rest was prescribed. With symptoms failing to improve the patient attended the emergency department where a plain film radiograph was taken. Based on the radiographic findings and history an urgent specialist orthopaedic opinion was sought. The "spotted bone" lesions seen on plain radiographs and the history of pain failing to resolve with initial treatment, warranted further investigation with Magnetic Resonance Imaging (MRI) (Figure 1).

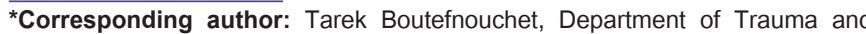
Orthopaedics, Queen Elizabeth Hospital, University Hospital Birmingham, Mindelsohn Way, Edgbaston, Birmingham, United Kingdom, Tel: +44 7809677302; E-mail: tboutefnouchet@hotmail.com

Citation: Boutefnouchet T, Laios T, Kalogrianitis S (2015) Osteopoikilosis: Avoiding Misdiagnosis of this Unusual Incidental Finding. A Case Report. J Orthop Res Physiother 1: 011

Received: May 29, 2015; Accepted: August 06, 2015; Published: August 20, 2015
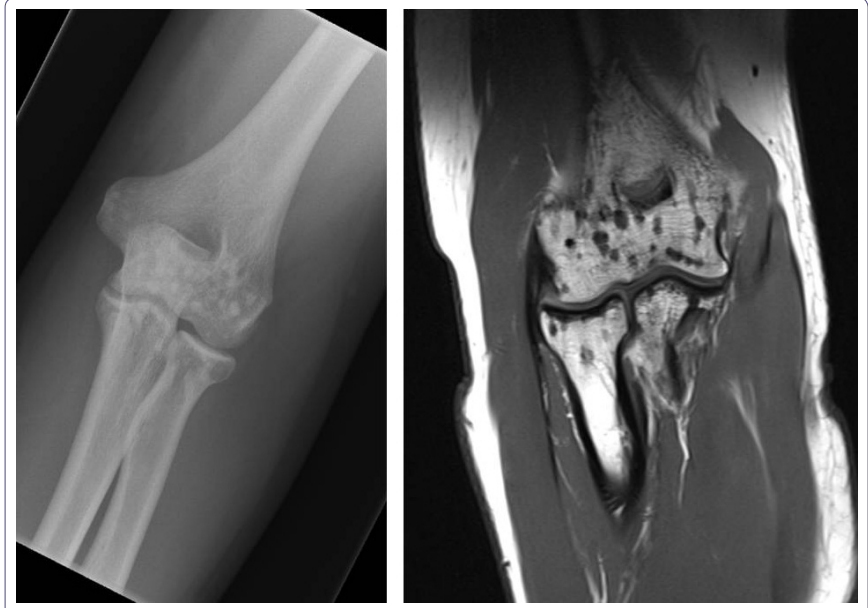

Figure 1: AP plain film radiograph and coronal section MR sequence of the left elbow showing osteopoikilosis.

The plain film radiographs showed multiple radio-opaque small lesions at the level of the distal humerus and proximal radius and ulna. The signal change depicted on the MR sequence demonstrates that these are dry multiple sclerotic lesions. The radiograph and MRI did not show evidence of any other abnormality. The images showed typical features of sclerosing bone dysplasia. The patient was followed up in the specialist upper limb and sports injury clinic after initial assessment, which did not reveal any obvious injuries. In addition, it was not considered necessary to undertake imaging studies of other body parts. The initial appearance of the radiographs raised concerns among the general practitioner and the casualty doctor, as it was a rare and unusual finding. It subsequently became apparent that the patient's father had also reported a known 'benign hereditary bone condition'. The condition was explained to the referring doctors and the patient reassured. Following a brief course of rest and physiotherapy the patient was able to resume normal level of function at the elbow joint including return to contact sports.

\section{Discussion}

Osteopoikilosis or 'spotted bone disease' is a rare benign sclerotic osteodysplasia, with an autosomal dominant hereditary pattern [1-3]. It has an estimated reported incidence of 1:50,000 with a male to female ratio of 3:2 [4]. The genetic predisposition to this condition has been linked to a heterozygous mutation of the LEMD3 gene [5]. Differential diagnoses for similar sclerotic bone lesions consist of benign hereditary sclerosing bone dysplasia, Paget's disease and osteoblastic bone metastases [6]. The list of other possible differential diagnoses to be considered can be extensive and include conditions such as: cortical desmoid, brodie abscess, synovial herniation pit, pseudocyst/subchondral cyst, enostosis, intraosseous ganglion cyst, fibrous dysplasia, stress fracture, healing fracture, bone infarct, myositis ossificans, melorheostosis and tumoral calcinosis $[7,8]$.

Each of the conditions outlined above has distinguishing anatomical distributions, clinical presentations and imaging features. Multiple benign sclerotic bone lesions with even peri-articular distribution are typical manifestation of osteopoikilosis also known as 
osteopathia condensans disseminata [9]. This is a benign autosomal dominant sclerosing dysplasia of bone. Patients are normally asymptomatic, systemically well and have normal blood tests. Several other genetic abnormalities can lead to sclerosing dysplasia of bone which results in deranged mechanism of endochondral and membranous ossification. Other hereditary variance of this condition include osteopetrosis, pyknodysostosis, osteopathia striata, progressive diaphyseal dysplasia, hereditary multiple diaphyseal sclerosis, hyperostosis corticalis generalisata [9]. This rare condition constitutes most frequently an incidental radiological finding associated with a different clinical presentation. Typically found as a red herring in a young physically active patient who undergoes radiographs for other indications. The aetiology remains unknown. Clinical assessment and plain radiographs are sufficient to make the diagnosis and further imaging studies such as MRI is only required in case of diagnostic dilemma or to help assess other causes of symptoms [10]. On isotopic bone scan osteopoikilosis does not appear as 'hot' lesion since there is no increased scintigraphic activity, distinguishing it form the more sinister metabolically active lesions. Furthermore, osteopoikilosis can present as an associated feature of Buschke-Ollendorff Syndrome (BOS), an autosomal dominant connective tissue disorder [11]. BOS is also known as scleroderma adultorum, which combines hamartoma, osteopoikilosis and multiple connective tissue nevi [11]. In the absence of typical skin lesions, plain radiographs demonstrating osteopoikilosis enable the diagnosis of BOS [12]. Other reports suggested connection to developmental dysplasia with vascular and urogenital defects [13] In such instance, further investigation and management must be considered in-line with the clinical features. The presence of bone lesions on radiographs is often an alarming feature especially to the non-specialist. Therefore, a combination of diligent clinical assessment and radiological investigation are needed to differentiate between benign conditions and the more serious lesions. Once other conditions have been excluded osteopoikilosis does not require further treatment. Simple analgesia, reassurance and NSAIDs combined with rest and physiotherapy are sufficient to control concomitant low-grade soft tissue injury. Unless there is evidence of systemic manifestation or loss of function patients with osteopoikilosis do not require specialist follow-up.

Osteopoikilosis remains a rare incidental finding detected on plain radiographs performed out of concern for a different clinical problem. The general medical community should be educated about this rare but potentially alarming finding. Differential diagnoses and associated features were outlined above. The case report demonstrates typical presentation, clinical and imaging features of osteopoikilosis. Once more serious conditions are excluded patients should be reassured and educated so as to avoid any further concerns and avoid the need for invasive diagnostic or therapeutic procedures.

\section{References}

1. İnci MF, Vurdem UE, Gümüș H, İnci $R$ (2012) Case report of a patient with osteopoikilosis. Rheumatology International 32: 2829-2832.

2. Borman P, Ozoran K, Aydoğ S, Coșkun S (2002) Osteopoikilosis: report of a clinical case and review of the literature. Joint Bone Spine 69: 230-233.

3. Benli IT, Akalin S, Boysan E, Mumcu EF, Kiș M, et al. (1992) Epidemiological, clinical and radiological aspects of osteopoikilosis. J Bone Joint Surg $\mathrm{Br} 74$ : 504-506.

4. Carpintero $P$, Abad JA, Serrano $P$, Serrano JA, Rodríguez $P$, et al. (2004) Clinical features of ten cases of osteopoikilosis. Clin Rheumatol 23: 505-508.

5. Pouchot J, Cellier C (2011) Clinical images: Osteopoikilosis. Arthritis Rheum 63: 2150

6. Bidarkotimath S, Murlimanju BV, Dhananjaya KV (2012) Radiology and morphology of spotted bone: a case report with review of literature. Clin Ter 163: 137-139.

7. Gould CF, Ly JQ, Lattin GE Jr, Beall DP, Sutcliffe JB 3rd (2007) Bone tumor mimics: avoiding misdiagnosis. Curr Probl Diagn Radiol 36: 124-141.

8. Martinez S, Vogler JB 3rd, Harrelson JM, Lyles KW (1990) Imaging of tumoral calcinosis: new observations. Radiology 174: 215-222.

9. Inde LL, Forrester DM, Gottsegen CJ, Masih S, Patel DB, et al. (2011) Sclerosing bone dysplasias: review and differentiation from other causes of osteosclerosis. Radiographics 31: 1865-1882.

10. Woyciechowsky TG, Monticielo MR, Keiserman B, Monticielo OA (2012) Osteopoikilosis: what does the rheumatologist must know about it? Clin Rheumatol 31: 745-748.

11. Blum AE, Hatter A, Honda K, Lu K (2011) An unusual presentation of Buschke-Ollendorff syndrome. J Am Acad Dermatol 65: 25-26.

12. de la Salmonière $P$, Janier $M$, Chemlal K, Lazareth I, Carlotti $A$, et al. (1994) [Buschke-Ollendorff syndrome]. Ann Dermatol Venereol 121: 718-720.

13. Gunal I, Kiter E (2003) Disorders associated with osteopoikilosis: 5 different lesions in a family. Acta Orthop Scand 74: 497-499. 